\title{
There is no 'l' in Team: Reflections on Team-Based Content Development at the National Museum of Australia
}

\author{
GUY HANSEN
}

Tn recent years one of the most important trends in the development Lof history exhibitions in major museums has been the use of interdisciplinary project teams for content development. This approach, often referred to as the team-based model of content development, has, in many institutions, replaced older models of exhibition production built around the expertise of the curator. The implementation of team-based models has had a profound impact on the way exhibitions are produced. When done well it has helped deliver exhibitions combining a strong focus on audience needs with in-depth scholarship and collections research. In some contexts, however, the tyranny of the team has given rise to a form of museological trench warfare in which different stakeholders struggle 
for creative control of an exhibition. In this article I will explore some aspects of the team-based approach with reference to the development of the opening suite of exhibitions for the National Museum of Australia (NMA) in 2001. My observations are drawn from my experience as the lead curator of the Nation Gallery, one of the NMA's opening exhibitions.

The concept of exhibitions as the product of interdisciplinary teams runs counter to popular perceptions of how content is developed in museums. For the most part the public face of museum content is the 'curator', a term usually understood as a person who administers and organises a collection and has oversight over how it is displayed. They are said to possess a 'curatorial eye' reflecting a strong sense of connoisseurship and a high level of subject expertise. Curators are sometimes thought of as auteurs, selecting what will be collected, displayed, and interpreted. This understanding of curatorial work is reinforced in popular media when curators are used to explain the significance of objects and artworks. Auction houses provide curators to vouch for the authenticity and significance of artworks and reassure potential buyers of their discernment. Exhibitions are often presented, or reviewed, as being authored by a curator.

This public image of curators as key decision makers is far removed from the reality of working life within museums. Rather than well-dressed connoisseurs, curators are much more likely to approximate your average stressed public servant. Instead of spending their days surrounded by beautiful objects - which are now safely stored in a museum warehouse - today's curator is more likely to be an office worker who spends their time sending and reading emails, drafting letters, answering the phone and attending meetings.

This discrepancy between the public image and reality of curatorial work reflects the changing role of curators in museums over the last thirty years. The care and management of museum collections is no longer the sole domain of the curator. The traditional guardianship of collections, implied in the older curatorial title 'keeper', has been replaced by the discipline of collections management. Registrars and conservators have joined curators as custodians of collections. Exhibitions have also become increasingly complex as more display techniques have become available. Other communication specialists, including designers and multi-media 
experts, are now essential parts of exhibition development teams. As the scope and size of exhibitions has grown there has been an erosion of the curator as the major author of content. Curators are now one voice amongst many who contribute to the development of exhibitions. Project managers, marketers, educators, collection managers, designers and publicists all play a crucial role in the development of content in museums. Rather than being an auteur, curators have now become, to use the language of modern management theory, one stakeholder amongst many in content production.

Before discussing how the team-based model of content development was introduced at the National Museum of Australia it is worth considering why it is important to understand the internal production processes used by museums. Museum history is often analysed as a distinct type of historical knowledge or discourse. Scholars such as David Lowenthal, Michael Wallace, and Roy Rosenzweig, to list but a few, have dissected museum exhibitions revealing how they present celebratory, partial and mythological accounts of the past. ${ }^{1}$ Reviewing this scholarship provides an insight into how history is used, or appropriated, in museums. While useful in providing cautionary tales about some of the worse excesses of history museums, such discussions rarely look beyond the exhibition hall. The internal world of how exhibitions are produced remains obscure.

A critical reassessment of the type of history produced in museums was also a key part the writings associated with the 'new museology' which emerged in the late 1980s. The Museum Time Machine ${ }^{2}$ and The New Museology, ${ }^{3}$ for example, argue that the representations of the past found in museums are constructed and partial, often reflecting the values of the dominant culture of the society in which they operate. Individual case studies emphasised how some groups in society, such as women and indigenous peoples, are under represented or stereotyped in museums. The new museology reflected a strong commitment to social inclusion, community access and multiculturalism. It was in effect a manifesto for change: museums needed to be more democratic and accessible. For museums to change, however, changes would need to be made to the way exhibitions were produced.

In Australia Tony Bennett's The Birth of the Museum is one of the most important books to postdate the new museology. It provided an 
account of the formation and development of the museum as a cultural form in the nineteenth and twentieth centuries. Bennett's objective was to expose the political context and power relations implicit in the way museums function within society. Taking inspiration from Michel Foucault's concept of 'heterotopias', and drawing heavily on Australian examples, Bennett compared museums to other cultural forms, such as travelling fairs and international exhibitions, leading him to conclude that museums 'formed a part of new strategies of governing aimed at producing a citizenry which ... would increasingly monitor and regulate its own conduct'. ${ }^{4}$ Bennett's work has been carried forward by authors such as Chris Healy and Kylie Message, both of whom have explored the cultural function of museums. ${ }^{5}$

The analysis of history museums provided by cultural studies scholars such as Bennett explores the history and cultural function of museums. It does not, however, provide an insight into what it is like to do history in a museum. In effect, museums are treated as texts which can be deconstructed or used as examples of social control. While this provides a reading of exhibition content in its finished form it does not examine the mechanics of how exhibitions are produced. This is not a criticism of the cultural studies engagement with museums, but rather a recognition its limits.

In addition to the cultural studies assessment of museum history there is also a professional literature designed to serve the needs of museum studies' students. A leader in this field is the University of Leicester, which established its museum studies program in 1966. One of the first universities in the world to provide vocational training for museum professionals, Leicester began to produce a series of textbooks which would become staples for museum studies courses around the world. These covered a range of topics, including museum management, public programs, museum education, and conservation techniques and collections management. These references set out to establish new standards of professional practice in a rapidly growing industry.

In terms of history curatorship the most important work to be published by Leicester was by Gaynor Kavanagh. Kavanagh wrote extensively throughout the 1980s and 1990s exploring the professional practice of history curators. History Curatorship, which was published in 1990, remains one of the few books to explore the 
development of history curatorship as a distinct profession. Kavanagh argues that the rapid growth of history museums in Britain in the late twentieth century was not matched by a parallel growth in trained museum professionals. The result was that curatorial practice lacked a firm theoretical foundation. As she describes it, 'there is no strong central core of theory and there has been little, if any, rigorous consideration of history practice, let alone challenge to $i^{\prime}{ }^{6}{ }^{6}$ History curatorship, as such, lacked self awareness: 'ideas of the curator's responsibility to record and represent the past are to be found more often implicitly expressed in direct curatorial activities, such as exhibition, rather than explicitly through debate and challenge within the profession itself. ${ }^{7}$ Furthermore, she said, 'if there is some form of intellectual basis to the work, say a notion of a "social and material past", it is largely unexplored other than indirectly through curatorial activity'. ${ }^{8}$

Kavanagh's analysis is an important first step in understanding the possibilities of history exhibitions. She outlines some of the major interpretative tools at the disposal of curators, including exhibition text, sounds, images and activities. Kavanagh also counsels curators to be more aware of their audience, emphasising that a visit to a museum is fundamentally a social phenomenon: 'Museum visitors are not one audience but many, with diverse needs and expectations. ${ }^{\prime 9}$ This description of exhibition types and museum audiences provides the beginnings of a vocabulary for discussing curatorial practice. These analytical tools allow Kavanagh to begin to explore how underlying conceptual frameworks inform curatorial practice. Kavanagh's work still stands today as the most detailed discussion of curatorial practice in history museums and is particularly instructive in understanding the successes and failures of British social history museums. Her analysis, however, is still very much focused on the end product of the exhibition development process.

In the Australian context there is a small but growing literature which is beginning to shed light on the internal workings of museums. For example Andrea Witcomb has written about the creation of the National Maritime Museum. ${ }^{10}$ Brian Crozier has written about his experiences as curator at the Queensland Museum. ${ }^{11}$ Richard Gillespie has discussed the challenges of the Melbourne Museum. ${ }^{12}$ More recently Kirsten Wehner, and Martha Sear have written about the challenges of delivering exhibitions at the 
National Museum of Australia. ${ }^{13}$ These authors have provided a view into the world of how history exhibitions are conceived and executed. For the most part, however, they do not address how the internal management processes of museums impact on content development. This article is designed to provide some preliminary comments on the emergence of the team-based content development model at the National Museum of Australia.

\section{The Team-Based Model}

The team-based model of content development emerged in the United States in the 1980s and is now used widely used around the world. A description of this model can be found in Barry Lord and Gail Dexter Lord's Manual of Museum Exhibitions. Under this model exhibition content is produced by a team consisting of representatives of key sections of museums including education, evaluation, finance, collections management, security, design, marketing and curatorial. Each team member is seen as an advocate for their own area of interest. The team is overseen by an exhibition coordinator and a project manager. All key content decisions are controlled by the institution's Director. ${ }^{14}$ Rather than content being driven by a single expert, a role usually occupied by a curator, the team-based model for developing content is a process of consensus building.

Compromises are made; decisions negotiated.

This portrayal of the team-based model is a high level description of how many museums operate. The precise details of how this model operates on the ground differ from museum to museum. Variations in its operation also occur from project to project. Each exhibition brings with it its own particularities and personalities which impact on how content is developed. That said it is clear that there has been a major shift in exhibition development processes around the world toward the team-based model. In the American context a series of informal surveys published in the Exhibitionist, the journal of the National Association for Museum Exhibition (USA) indicated that in 199560 per cent of major museums were using a team-based model for exhibition development and that this had grown to 100 per cent in $1999 .{ }^{15}$ While there are no similar figures available for Australia, anecdotal evidence suggests a similar pattern holds true. 
What then are the reasons for the widespread adoption of the team-based methodology? One of the primary causes is the increasing cost and complexity of exhibitions. It is no longer possible for museums to delegate, to a single curator, the delivery of projects worth potentially millions of dollars. The need for increased accountability has made it essential that modern project management techniques be utilised to ensure that exhibitions are delivered on time and on budget. The range of display techniques used in exhibitions has also expanded. Today museums can utilise static display techniques through to high-end multi-media environments. The skill sets used in delivering exhibitions has grown almost exponentially. The combination of these factors has required most museums to move to some form of team-based content development.

The introduction of the team-based approach was, however, not simply a function of the need for better project management. Elaine Guriane, in her anthology Civilizing the Museum, argues that the team-based approach was developed primarily as a political strategy to break the, 'closely held monopoly of curators and designers over exhibition creation'. ${ }^{16}$ This was necessary, she argued, because curators often ignored the needs of museum visitors and produced esoteric exhibitions. This critique of curators was a common feature of the new museology. For example in her 1994 work, Museums and their Visitors, Eileen Hooper-Greenhill railed against curatorial control. 'For too long, museums have defended the value of scholarship, research and collection at the expense of (her emphasis) the needs of the visitors' ${ }^{17}$ Underlying Hooper-Greenhill's call for change was the belief that curators traditionally played the role of a power-broker, defining exhibition content according to their own point of view. Other museum professionals were expected to fall in line. Designers were treated as 'functionaries'. Educators were often brought in at a late stage in a remedial role, and forced to, 'make the best of a bad job'. ${ }^{18}$ For Hooper-Greenhill the 90 s ushered in a new era of museums in which, 'the balance of power in museums is shifting from those who care for objects to include, and often prioritise, those who care for people. ${ }^{19}$ By the end of the 1990s Hooper-Greenhill and Guriane, amongst other writers, had helped establish a new rhetoric of inclusion in museum practice. A key part of this rhetoric was that creative control of exhibitions needed to be wrested away from curators. 


\section{The Team-Based Model and the National MUSEUM OF AUSTRALIA}

When I joined the National Museum of Australia in 1991 it was a modest organisation with approximately 40 staff. The museum's collections were stored in a number of rented warehouses in the northern suburbs of Canberra. It was a museum waiting to happen. This was a frustrating period in the museum's history as debate raged as to when, where and if to build a national museum. Ironically this period of uncertainty provided the curators working at the museum great freedom. There were no restraints on collections access. Exhibition development, modest though it was at this time, was led by curators. The pressures of delivering a new museum had not yet made themselves felt.

Looking back on this period I can now see that the National Museum was operating in an older museum culture which emphasised the importance of the collection. It was inevitable that this structure would change as the museum moved from being a small secretariat, who managed the National Historic Collection, into a fully realised national cultural institution. While changes to the National Museum's work culture began under the directorships of Margaret Coaldrake and Bill Jonas in the early to mid 1990s, the tipping point occurred in 1996, when, after years of debate, the Commonwealth government finally committed itself to building a permanent home for the National Museum. Prime Minister John Howard announced that the museum would open in 2001 as the centrepiece of the Australia's centenary of Federation celebrations. In a very short period of time the museum moved from being a sleepy backwater to becoming one of Australia's major cultural institutions.

One of the key challenges for museum management in 1996 was how to deliver a $\$ 155$ million dollar project in a little over four years. This involved the design and construction of a new museum building as well the delivery of a suite of permanent exhibitions. The museum had to rapidly shift from caretaker role to major project delivery. Throughout 1997 and 1998 curatorial staff within the Museum commenced work on a series of exhibition proposals for the new museum. It soon became clear, however, that the Department of Communications and Arts, the government Department responsible for the construction of the museum, seriously doubted the capacity of the museum to deliver the content required in the short time frame 
available. The Department sought advice from the international consulting firm Ralph Applebaum and Associates on possible ways of delivering the new museum. The Applebaum report proposed the creation of a museum which was primarily experiential. Their design solutions emphasised the use of multimedia and immersive environments rather than historical exhibits. ${ }^{20}$ While the Applebaum proposal was not pursued it reflected a tendency by the Department to look outside the NMA for ways of developing content.

The growing sense of urgency surrounding the project was reflected in the appointment of Dawn Casey, a senior bureaucrat from the Department of Communication and the Arts, as the new Director of the Museum in 1999. Casey came to the job with a clear mission: get the museum built. Her previous job in the Department had been as head of the Construction Coordination Task Force responsible for building the museum. One of Casey's key advisors was Elaine Gurian, an American museum expert well known for her involvement in the Washington Holocaust Museum and the Boston Children's Museum. Partly on Gurian's recommendation Casey also appointed Sean Sweeney, a project manager who had been involved in the construction of Te Papa, the National Museum of New Zealand, to provide scheduling and budgeting advice.

Sweeney and Gurian were to work closely with Casey to implement a new staff structure and plan the opening of the museum. Casey, Sweeney and Gurian played a key role in transforming the museum into a modern cultural institution. They brought with them a range of assumptions drawn from contemporary museum management theory, particularly as it is understood in the United States. Central to this was a team-based model of content development.

One of the first decisions made by Casey and her support team was that content development would not be driven directly by curatorial staff. Rather, exhibition teams would be coordinated by external interpretative planners. These planners were drawn from the Boston design firm, Amaze. It is important to note that Amaze Design were not directly in the employ of the NMA but were rather part of an alliance of companies building the museum headed by the Department of Communication and the Arts. The role of the interpretive planners was to act as intermediaries between NMA staff and designers. Under this model curators would no longer be referred to as curators but would instead be known as 'content 
developers.' This reclassification of curatorial staff sent a clear message that the curators should focus on the research and object identification phase of exhibition development. Communication specialists, in this case the team of interpretative planners, would work with designers to realise the shape and form of the exhibitions.

The team of interpretative planners from Amaze Design were highly professional and brought considerable experience in developing large scale tourist facilities. They also benefited from having an outsider perspective and curiosity about Australia culture. They lacked, however, any real knowledge of Australian history and struggled, at times, to understand the shape and type of stories which could be told in an Australian museum. The Amaze team initially held a number of workshops with historians, writers and cultural commentators in an attempt to harvest content and quickly identify exhibition ideas. The lack of consensus about a grand narrative in Australian history, however, made it far from clear as to the best way to proceed. After tentatively exploring a range of content ideas from outside the museum, the Amaze team turned to NMAs existing curatorial team for exhibition ideas. While curatorial staff had initially been suspicious of Amaze they in the end formed an effective partnership to produce the exhibitions.

Another aspect of the application of the team-based model at the NMA was the decision to employ a team of writers to prepare exhibition text. In what became a laborious and frustrating process 'content developers', or curators, would prepare briefing notes on each object or panel which required text. Writers would then summarise these notes at the requisite word length. This was done, it was argued at the time, because curatorial staff lacked the skill to write for a popular audience. Unfortunately the use of external writers did not achieve the desired results. Errors inevitably crept into the text as writers paraphrased notes that they did not fully understand for exhibits they had never seen. For the most part text had to be rewritten by curatorial staff with the assistance of an editorial team. In hindsight the use of professional writers in the content development process would have been more useful if the writers had been fully integrated in exhibition development teams.

Perhaps the most important aspect of the team-based model was that all exhibition teams were established as projects with clear time lines and budgets. Team leaders were required to report monthly on 
progress made against agreed milestones. A centralised project management team closely monitored the progress of all exhibitions. In this way the Museum's executive had ready access to information on the status of the development of all exhibitions. This system of surveillance helped ensure that any problems with the development of exhibitions were identified as early as possible.

This application of strict project management methodologies allowed the NMA's executive to keep firm control of the content development process. In the context of simultaneously producing several major exhibitions in a building which was still under construction for an opening day which could not be changed, this ability to track the development of each exhibition was vitally important. While curatorial staff at times chaffed under the constraints of the project time line and budget, the unique set of circumstances surrounding the opening of the NMA necessitated this highly planned approach.

One negative consequence of this adherence to a project management methodology, however, was that the creative process of exhibition development was seen as being equivalent to production line. Each exhibition was broken up into a series of inputs which were scheduled on a Gantt chart. Content development became a phase which occurred early in a project's life. However, as the project went on it became clear that curators were needed throughout the life of the project. As the staff most familiar with the key messages of exhibitions, curators needed to comment on graphic production, audio visual components and object installation. This experience demonstrated the limitations of the production line model for exhibition development. Producing exhibitions is not like building motorcars. Whereas workers on a production line install their parts on a chassis and then allow the vehicle to move on down the line, curators need to walk with an exhibition from its inception to completion.

The suite of exhibitions which were produced for the opening of the NMA were Tangled Destinies, an environmental history exhibition; Eternity, an exhibition which displayed objects in terms of the emotions they represented utilising first person quotes to explain their significance; Horizons, a migration history display; Nation: Symbols of Australia, an exploration of Australia's symbolic vocabulary in material culture and Gallery of First Australians, an exhibition which focused on Australia's indigenous peoples. 
Significantly all of these galleries emerged directly from proposals developed by curatorial staff and were opened on time and within budget.

The exhibition for which I was the lead curator was Nation: Symbols of Australia. This exhibition set out to explore Australian history and culture through the lens of national symbols. The intention was to provide a multi-voiced, contingent view of national identity. Making symbols the primary focus of the exhibition allowed the museum to play to its strengths by focusing on the visual, aural and material culture record of Australian history, rather than struggle with narratives more appropriately explored in a monograph. Symbols to be explored included both official symbols such as the flag, coat of arms and Anzac, as well as popular culture symbols such as the digger, the kangaroo, suburbia, and the use of indigenous imagery in national celebrations. Reviewing the history of these symbols and how they were used provided a range of views or voices about national identity, varying according to the time and context in which they were produced.

While the Nation exhibition had a strong curatorial argument at its core, it was inevitably adapted as it went through the team-based content development process. A strong desire by members of the Museum's council and executive for a chronological account of Australian history saw the inclusion of a time line of major events in Australian history. Also added to the exhibition were modules dealing with the history of communications and transport. These additions, while attractive and interesting exhibits, were tangential to the exhibition's central argument and did impact on the overall coherence of the exhibition. The Nation gallery was not alone in having its content changed and adapted throughout the exhibition development process. All exhibitions went through an extensive process of design and redesign. At times discussions in relation to the final form of exhibition content were highly charged. Under the teambased model the final sign off for content was made by the Museum's Director, Dawn Casey.

In this difficult period of finalising the NMA's opening suite of exhibitions it is interesting to reflect on where the major points of conflict lay. Surprisingly, despite the later response of some conservative critics, it was not political sensitivities which dominated internal debates over the final form of the museum's exhibitions. 
Rather it was the much more immediate concerns over deadlines, available floor space and budget constraints. It was these pragmatic concerns which necessitated some of the largest changes to exhibition content. In the instance of the Eternity, for example, the exhibition's content was reduced by 50 per cent for both budgetary and space reasons. In the case of the Nation a third of proposed exhibition modules were cut. Changes in the building design also necessitated a significant reworking of exhibition content. Battles over window treatments and the positioning of staircases within exhibition spaces became a major source of controversy. The need to get the job done became an all pervasive driving force within the museum.

While pragmatic concerns over budget and space dominated the foreground in the lead up to the opening of the museum, significant political pressure was also exerted. The Museum's executive worked hard to protect staff from this pressure. Documents obtained by the Sydney Morning Herald via a freedom of information request revealed how David Barnett, a museum council member, attempted to intervene in the development of content for the museum's exhibitions. Barnett, a former Liberal party staffer and author of the authorised biography of John Howard, sent a memo deriding draft exhibition text to Tony Staley, the chair of the NMA council and former president of the Liberal Party, in October 2000. Barnett was alarmed by what he saw as systematic bias in the museum's displays. 'The museum should not be a contributor to the reworking of Australian history into political correctness, which, as we saw at the [Olympic] Games opening ceremony, is taking hold.' He went on, 'perhaps as I plod through all this I will come across people who served their country, sacrificed themselves for it, made it a better place, or even what it is today'. He was horrified to find that the museum included people such as the antinuclear demonstrator Benny Zable and Lenin Peace Prize recipient William Morrow within exhibits. 'These people are not my heroes', he wrote, 'Why Benny Zable and not Hugh Morgan, who created wealth for Australians and jobs for Australians? ... What about H.R. Nicholls and Charles Copeman for the Hall of Fame ... what about Chris Corrigan?'. Barnett concluded, 'I would have thought a National Museum in the national capital might have managed interesting exhibits dealing with the founding fathers and telling us who past prime ministers have been and something about them without being egregious' ${ }^{21}$ Barnett's comments revealed a longing for a more traditional and 
triumphalist account of national history, one which was aligned with his own personal ideology. ${ }^{22}$

After receiving Barnett's memo Staley instituted a review of label text. At the recommendation of Emeritus Professor Geoffrey Blainey, Graeme Davison of Monash University was approached to provide a second opinion. Davison reviewed the text and, while finding some minor errors, concluded that the exhibits were based on sound scholarship. Furthermore, Davison completely rejected Barnett's allegation of any systematic bias in the label text. He expressed the view that, "while individual items may express interpretations that David might read as PC, they are not preponderant'. ${ }^{23}$ Davison played and important role in reassuring the majority of council members that the exhibitions could go ahead largely unchanged. His role as an independent arbiter also helped to protect staff from direct criticism from Council members.

While some members of the Museum's council were displeased with the exhibition content the general public responded differently. Visitor response to the NMA's opening exhibitions, as gauged by ongoing surveys, found that more than ninety per cent of visitors were highly satisfied with their visit. ${ }^{24}$ Attendance numbers in the opening year also suggested that the museum was a success. By the time the first birthday cake was wheeled in, more than 900,000 people and visited the NMA.$^{25}$ In terms of the critical reviews of the museum the response was again largely positive. ${ }^{26}$ The exception to this was a small but influential group of conservative commentators who condemned the museum for presenting a 'black arm band' view of Australian history. Miranda Divine, for example, argued that the main message of the museum was 'one of sneering ridicule for white Australia'. ${ }^{27}$ Keith Windschuttle described the museum as 'an expensive relic of postmodern theory'. ${ }^{28}$ Members of the NMA's Council who had previously expressed their concerns over content again called for a more celebratory account of Australian history. ${ }^{29}$ Following these criticisms the government instituted a review of the NMA's exhibitions and programs. Known as the Carroll Review, after the review committee's chair Dr John Carroll, the report found that there was no systematic political bias in the NMA's exhibitions. That said however, the Review called for a reworking of the museums exhibitions to provide a narrative of nation building that 
would showcase 'exemplary individual, group and institutional achievements' ${ }^{30}$

\section{CONCLUSION}

What conclusions can we draw about the application of the teambased model to the development of the NMA's opening exhibitions? In terms of project delivery the team-based model was a success. The Museum opened on time and on budget. The teams of interpretative planners, designers and museum curators, had, in most cases, worked together successfully. Not all of the exhibitions, however, were unqualified successes. Some areas of the museum suffered from the process of compromise and change that was inherent in a project as large and complicated as the opening of a new national museum. Some staff became disillusioned with the exhibition development process and chose to leave the museum prior to opening. While to some extent this 'churn' of staff was inevitable, it did reflect the stresses which emerged from struggles over the creative control of exhibitions.

Perhaps one of the most interesting lessons to emerge from the development of the NMA's opening suite of exhibitions was the central role played by the museum's curators. While in the early stages of the project efforts were made to source content from outside the Museum in the end it was the proposals put forward by NMA's curatorial staff that were developed. Similarly the attempt to reclassify curators as content developers failed to gain acceptance with museum staff. As each of the exhibitions were developed it became increasingly clear that curators were essential to maintaining the coherence of the exhibits.

While curators remained at the centre of producing content for the NMA it is also clear that their creative control of the final product was mediated by both internal and external factors. Graeme Davison has described this process as building an 'institutional consensus' ${ }^{31}$ For example, in the case of the Nation, the content for the exhibition underwent a process of continuous consultation and revision in the lead-up to opening. This included discussions between NMA curatorial staff and interpretative planners as well as input from exhibition designers and the building's architect. Advice was also sought from external experts and audio visual producers. The NMA's executive provided guidance, as did the Museum's conservation and registration sections. Final approval for the exhibition content was 
provided by the Museum's council and Director. This collaborative process of content development is far removed from traditional notions of the curator as the major author of exhibition content.

While exhibitions are produced by large interdisciplinary teams, curators still have a responsibility to promulgate a clear vision of what an exhibition is trying to achieve. While teams are an effective way of harvesting a range of skill sets and ideas, they can easily become dysfunctional as different team members compete for creative control of content. External factors such as budget constraints or political pressure can also impact on the content development process. In this context it is essential that curators take on a leadership role similar to that of a film director. While many skill sets are brought to bear in realising a film it is the director who has responsibility to ensure the movie makes sense and has an overall integrity. Similarly curators need to stress test content as it is developed for an exhibition to ensure it is 'on message'. Exhibitions which are developed without such leadership run the risk of losing coherence.

What has happened at the NMA since opening in 2001? Exhibitions continue to be developed using a team-based model. As part of this approach strict project management methodologies are now considered an essential part of the museum's work culture. The shift from delivering permanent exhibitions to smaller temporary exhibitions has also seen curators reassert themselves in a leadership role in content development. This is reflected in the way the NMA no longer uses interpretative planners as intermediaries between curatorial staff and designers nor does the museum employ external writers to compose exhibition text. In 2004 incoming Director Craddock Morton formally reinstituted the use of professional title 'curator' within the NMA, partly in recognition of the role they play in developing content within the museum. The Nation exhibition, on which the observations in this article are based, remained on display until 2009.

Producing history exhibitions is a practical business. In classic economic terms, content is generated within a frame work of available resources. As with the rest of the economy the 'scarcity principal' is a major driver of decisions about what gets to be represented in public accounts of the past. While driven by ideas and passion for their subject area, curators must inevitably engage in how 
projects can be funded and delivered. They must not only develop the content but also build support for a project. It is here that the practice of public history intersects with the realities of project management and institutional politics. Project management and team-based content development models are now a key part of curatorial work. Understanding this shift in the way museums work provides another layer of understanding into how history is produced in museums.

\section{ENDNOTES}

${ }^{1}$ See for example, David Lowenthal, The Past is a Foreign Country Cambridge University Press, 1985; Warren Leon and Roy Rosenzweig, History Museums in the United States, University of Illinois Press, Urbana, 1989; Michael Wallace, 'Visiting the past: History museums in the United States' in Roy Rosenzweig, Susan Benson and Stephen Brier (eds), Presenting the Past, Temple University Press, Philadelphia, 1986.

${ }^{2}$ Robert Lumley (ed), The Museum time-machine: putting cultures on display, Routledge, London, 1988.

${ }^{3}$ Peter Vergo (ed), The New museology, Reaktion Books, London, 1989.

${ }^{4}$ Tony Bennett, The Birth of the Museum, Routledge, London, 1995, p8.

${ }^{5}$ See Chris Healy, From the Ruins of Colonialism: History as Social Memory, Cambridge University Press, Cambridge, New York and Melbourne, 1997; Chris Healy and Andrea Witcomb (eds), South Pacific Museums: Experiments in Culture, Monash ePress, Melbourne, Sydney, 2006; Kylie Message, New Museums and the Making of Culture, Berg, Oxford and New York, 2006.

${ }^{6}$ Gaynor Kavanagh, History Curatorship, Leicester University Press, London, 1990, $\mathrm{p} 11$.

7 ibid, p55.

8 ibid, p61.

9 ibid, p135.

${ }^{10}$ Andrea Witcomb, Re-Imagining the Museum: Beyond the Mausoleum, Routledge, London, 2003.

${ }^{11}$ Brian Crozier and Helen Gregory, 'Creating "A Lot On Her Hands"', Labour History, no 8, 2003, pp 89-101. Also see 'What was it like: a perspective on history in museums', paper presented at National Museum of Australia Collections Symposium 2009, transcript (Online). Available: www.nma.gov.au/audio/collections_symposium_2009.

${ }^{12}$ Richard Gillespie, 'Making an exhibition: One gallery, one thousand objects, one million critics', Meanjin, vol 60, no 4, 2001, pp111-48.

${ }^{13}$ Kirsten Wehner and Martha Sear, 'Engaging the material world; object knowledge and Australian Journeys', in Sandra Dudley (ed), Museum Materialities: Objects, Engagements, Interpretations, Routledge, 2009.

${ }^{14}$ Barry Lord and Gail Dexter, The Manual of Museum Exhibitions, AltaMira Press, Walnut Creek, CA, 2002, p5.

${ }^{15}$ Martha Morris, 'Recent Trends in Exhibition Development', Exhibitionist, Vol.21 No.1 Spring 2002 pp8-11. 
${ }^{16}$ Elaine H Gurian, Civilizing the Museum: The Collected Writings of Elaine Heumann Gurian, Routledge, London and New York, 2006, p163.

${ }^{17}$ Eilean Hooper-Greenhill, Museums and their Visitors London, Routledge, New York, 1994, p1.

18 ibid, p48.

${ }^{19}$ ibid, p1.

${ }^{20}$ Ralph Appelbaum Associates, National Museum of Australia: a casebook of concepts, Ralph Appelbaum Associates, 1997.

${ }^{21}$ Joyce Morgan, 'Howard's man: "Those people are not my heroes"', Sydney Morning Herald, 5 June 2001, p16.

${ }^{22}$ For an account of the political controversies surrounding the museum see Guy Hansen, 'White Hot History' Public History Review, vol 11, 2004, pp39 -51 and Guy Hansen 'Telling the Australian Story at the National Museum of Australia' History Australia, vol 2, no 3, 2005, pp90.1-90.9.

${ }^{23}$ ibid, p16.

${ }^{24}$ Submission by the National Museum of Australia to the National Museum of Australia Review of Exhibitions and Public Programs, 2003, p24.

${ }^{25}$ National Museum of Australia, Annual Report, 2001-2, p43.

${ }^{26}$ Submission by the National Museum of Australia to the National Museum of Australia Review of Exhibitions and Public Programs, 2003, p54.

${ }^{27}$ Miranda Divine, 'A Nation Trivialised', Daily Telegraph, 12 March 2001, p3.

${ }^{28}$ Keith Windschuttle, How not to run a museum: people's history at the postmodern museum' Quadrant vol 45 no 9, September 2001, p19.

${ }^{29}$ Joyce Morgan, op cit, p6.

${ }^{30}$ Review of the National Museum of Australia, Department of Communications, Information Technology and the Arts, 2003, p13.

${ }^{31}$ Graeme Davison, 'Museums and the culture wars: In defence of civic pluralism', Open Museums Journal, vol 8, August 2006, p9. 